\title{
Levels of scientific evidence of the quality of life in patients treated for oral cancer
}

\author{
Rocío Barrios ${ }^{1}$, Javier Montero ${ }^{2}$, Miguel-Angel González-Moles ${ }^{3}$, Pilar Baca ${ }^{4}$, Manuel Bravo ${ }^{4}$ \\ ${ }^{1}$ DDs, Postgraduate Research Fellow of the Spanish Ministry of Education. School of Dentistry. University of Granada \\ ${ }^{2} \mathrm{PhD}$, Associate Professor of Prothetic Dentistry. School of Medicine. University of Salamanca \\ ${ }^{3} \mathrm{PhD}$, Professor of Oral Medicine. School of Dentistry. University of Granada \\ ${ }^{4} \mathrm{PhD}$, Professor of Preventive and Community Dentistry. School of Dentistry. University of Granada
}

Correspondence:

School of Dentistry

University of Granada. Spain

Facultad de Odontologia

Campus de Cartuja s/n

18071 Granada, Spain

mbravo@ugr.es

\author{
Barrios R, Montero J, González-Moles MA, Baca P, Bravo M. Levels of \\ scientific evidence of the quality of life in patients treated for oral cancer. \\ Med Oral Patol Oral Cir Bucal. 2013 Jul 1;18 (4):e578-84. \\ http://www.medicinaoral.com/medoralfree01/v18i4/medoralv18i4p578.pdf

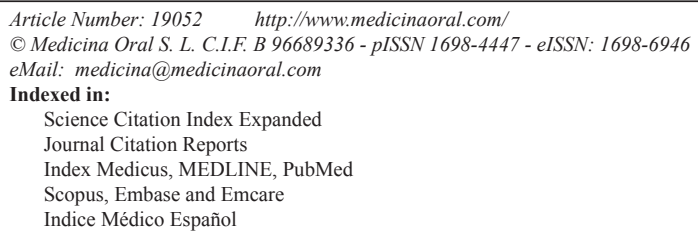

Received: 10/01/2013 Accepted: 03/02/2013

\begin{abstract}
Treatments used in cancer of the oral cavity have great impact on the physical, psychological and functional state of patients. There has been increasingly interest in evaluating the health-related quality of life using questionnaires among patients treated FOR oral cancer. Up to our knowledge no review on this theme has incorporated the level of evidence of the single identified studies. The objective of the present study is to determinate results and conclusions about the health-related quality of life of these patients, in view of scientific evidence. In general, the diversity of designs, level of evidence and questionnaires used for their assessment does not affect results, which indicate a decline in the health-related quality of life after treatment. This decline is greater when the tumor is large in size, and when radiotherapy is used, though the situation is seen to improve over the span of a year. Questionnaires on health-related quality of life provide concrete information regarding the impact of cancer treatment on patients.
\end{abstract}

Key words: Quality of life, oral cancer, questionnaire.

\section{Introduction}

Cancer of the oral cavity is a pathology of increasing significance worldwide. The approximately 263,000 new cases every year make it the most common form of head/neck cancer; mortality rates indicate that over half of these cases survive (127,654 deaths per year) (1). Such figures indicate that a considerable number of patients cope with the after-effects of the treatment: surgery or the habitual combination of surgery, radiotherapy and chemotherapy.

A patient endures stressful situations from the diagnosis of oral cancer. In advanced stages, and after treat- 
ment, changes associated with chewing, swallowing, salivating and speech are seen $(2,3)$. Thus, the patient's health-related quality of life (HRQoL) may be altered considerably.

For these reasons, there is growing interest in evaluating the HRQoL using questionnaires among patients treated for oral cancer $(4,5)$. The patient completed questionnaires are the most common method used to assess the HRQoL (2). They are composed for questions or items whose answers can be analyzed independently and be combined to obtain different domains (6).

The development of a hierarchy in the scientific evidence has allowed health professionals to do an evidence-based clinical practice (7). Up to our knowledge no review on HRQoL in patients treated FOR oral cancer has incorporated the level of evidence of the single identified studies. The aim of our study was to determinate results/conclusions about HRQoL drawn by studies of patients treated for oral cancer, and to identify possible differences according to the study design or level of scientific evidence.

\section{Material and Methods}

A bibliographic search was done using MEDLINE and Scopus databases, with the strategy ("oral cancer" OR "mouth neoplasms") AND "quality of life" AND "questionnaire" in the period 1966-Dic 2012. Quality of life was used as the main search term, as it is a more common keyword than HRQoL (8). Furthermore, studies included in the bibliographic references of these papers were identified. After this initial search, the abstracts were read and the full paper if necessary, in light of the inclusion criteria in this study. The articles were included if they assessed the HRQoL, psychological aspects and/or functional aspects of patients treated for cancer of the oral cavity, oral and lip cancer, and/or oropharyngeal cancer, using a HRQoL questionnaire. The studies that incorporated other head neck cancers (nasal cavity, nasopharynx, larynx...) were excluded. This process resulted in 79 articles, referring to 62 independent studies.

After that, the documents were classified according to their design as:

-Randomized clinical trials: randomized intervention studies where, after applying different treatments in cancer patients, the results are compared using HRQoL questionnaires.

-Studies of controlled cohorts: those evaluating the quality of life of the patients on one occasion (without repeated measurements) or on numerous occasions (longitudinal study), the results being compared with those of a control cohort or with populational data existing in the literature.

-Studies of non-controlled cohorts: longitudinal studies whose results were not contrasted with any other cohort.
-Transversal studies: those taking one measurement of the quality of life of patients without comparing results with any other cohort.

-Reviews: articles that offer an updated overview of the findings of previous studies.

Furthermore, the designs were coded according to the following levels of scientific evidence (9): $1++$ ) Systematic review or meta-analysis of randomized clinical studies of a high quality or randomized clinical studies with a very low risk of bias. $1+$ ) Systematic review or meta-analysis of randomized clinical trials that were well conducted or randomized clinical trials with a low risk of bias. 1-) Systematic review or meta-analysis of randomized clinical trials, or randomized clinical trials with a high risk of bias. $2++)$ Systematic review of cohort studies or case controls of high quality, or systematic review of cohort studies or case controls of high quality and entailing a low risk of confounding factors, bias or chance, and a high probability of causal association. $2+$ ) Studies of cohorts or case controls that were well conducted, with a low level of confounding factors, bias, chance and a moderate probability of causal association. 2 -) Studies of cohorts or case controls with a high level of confounding factors, bias, chance and a significant risk that the association was not causal. 3) Non-analytical studies, such as cross-sectional surveys or case series. 4) Expert opinions or non-systematic reviews.

No article selected for our study was excluded for methodological reasons $(10,11)$. The authors summed up the main results and conclusions from the articles included under the different types of study designs. To achieve final consensus, a focal group was organized consisting of the authors of this article and following the EuropeAid Evaluation Guidelines (12). Briefly, a focal group is a qualitative research technique that involves moderated meetings in the form of a structured, open group interview. After exposition and discussion of the different opinions, a final report was written up with the results and conclusions agreed upon.

\section{Results}

Table 1 shows the results of the bibliographic search conducted. There was an increase in the number of publications over time. We found that the general questionnaires were used in most often (European Organization for Research and Treatment of Cancer Quality of Life Questionnaires, EORTC-QLQ, closely followed by University of Washington Quality of Life Questionnaire, UW-QOL). Only four studies used the oral health impact profile (OHIP), a specific questionnaire for assessing changes in the oral health-related quality of life.

The main results and conclusions from the articles are presented according to their design in the table 2. Only 2 experimental studies were found: one study classified as $1++$ (maximum level of evidence), and another with 
Table 1. Summary of the bibliographic search.

\begin{tabular}{|c|c|}
\hline \multicolumn{2}{|l|}{ Number of articles } \\
\hline Period & \\
\hline 1984-1987 & 2 \\
\hline 1988-1991 & 2 \\
\hline 1992-1995 & 4 \\
\hline 1996-1999 & 11 \\
\hline $2000-2003$ & 9 \\
\hline 2004-2007 & 13 \\
\hline $2008-2012$ & 38 \\
\hline Total & 79 \\
\hline Location of tumor ${ }^{\mathrm{a}}$ & \\
\hline Oral cavity & 33 \\
\hline Oral and oro-pharyngeal cavity & 22 \\
\hline Oral cavity and lip & 6 \\
\hline Base of the tongue & 5 \\
\hline Oral cavity, oro-pharyngeal cavity and lip & 5 \\
\hline Bottom of the mouth & 4 \\
\hline Questionnaire used for $H R Q O L^{a}$ & \\
\hline EORTC-QLQ $^{\mathrm{b}}$ & 26 \\
\hline UW-QOL ${ }^{\mathrm{c}}$ & 22 \\
\hline PSS-HN ${ }^{d}$ & 8 \\
\hline $\mathrm{SF}-36^{\mathrm{e}}$ & 6 \\
\hline $\mathrm{OHIP}^{\mathrm{f}}$ & 4 \\
\hline Others $^{\mathrm{g}}$ & 15 \\
\hline Design & \\
\hline Randomized clinical trial & 2 \\
\hline Controlled cohort study & 10 \\
\hline Non-controlled cohort study & 29 \\
\hline Cross-sectional study & 34 \\
\hline Review & 4 \\
\hline
\end{tabular}

${ }^{a}$ Review articles not included. The sum of the articles of this section is not equal the total of articles found because some of them combine questionnaires listed in the table.

${ }^{\mathrm{b}}$ EORTC-QLQ: European Organization for Research and Treatment of Cancer Quality of Life Questionnaires.

c UW-QOL: the University of Washington Quality of Life. d PSS-HN: the Head and Neck Performance Status Scale.

e SF-36: Medical Outcomes Study Short Form 36-item Health Survey.

${ }^{\mathrm{f}}$ OHIP: Oral health impact profile.

${ }^{g}$ Studies not using EORTC, UW-QOL, PSS-HN, SF-36, or OHIP.

a level $1+$. There were 10 controlled cohort studies, with a $2+$ level of evidence, whose results were not conclusive. The 29 studies of non-controlled cohorts together with the 34 cross-sectional studies (level of scientific evidence 3) plus the 4 reviews found (level of evidence 4) make manifest that the patients treated with radiotherapy have a poorer HRQoL.

\section{Discussion}

Quality of life has been considered to be an important outcome parameter in oral cancer (8), which explains the increasing number of studies on HRQoL found over the time period analyzed here. There is great diversity in the questionnaires used, or even combined, perhaps due to the fact that the concept of HRQoL is associated with multiple functional and psychosocial factors. The existence of a gold standard with unified criteria would allow the studies to be compared in a more rigorous manner. Overall, however, they do manage to cover the most common problems in a structured way, proving to be a useful tool for enhancing communication between health professionals and patients, which is essential in the area of cancer $(6,13)$.

Despite the heterogeneity of the designs, the results/ conclusions are on the same line: a decrease in the HRQoL after treatment (14-22), which appears to parallel the magnitude of the tumor $(2,4,23-31)$, and the use of radiotherapy $(2,4,5,29,32-40)$. After a year, this declining trend turns around $(15,16,18,20,22,41-47)$. The improvement in HRQoL over time is a result to be taken with some caution. Coping mechanisms, or adaptation to a new situation, may be one reason, but we must not forget that the data are based on surviving patients without relapse.

The existence of two randomized clinical trials evidences the practicality of incorporating the measure of HRQoL in these types of studies. Accordingly, HRQOL would have sufficient scientific backing to become a key consideration in the treatment planning process, as in situations where there are virtually no differences in associated survival rates (48). Moreover, we should underline the lack of studies with controlled cohorts. The most of them compare the results of the patients with populational data or with the results of their partners/spouses whose life quality is likewise affected by the illness $(3,49)$. It would be interesting to carry out new research studies designed in such a fashion that each patient would have a control paired up by age and sex that would allow for comparison of results in a less biased way.

Despite therapeutic advances and enhanced survival, oral cancer patients inevitably face some decrease in HRQoL $(28,50)$. They are not always satisfied with the information received, especially in relation to the changes they experience in their lifestyle after treatment $(51,52)$. Health professionals have a variety of validated questionnaires, allowing them to familiarize themselves with the after-effects of oral cancer and therapy to the improvement of this communication. Online questionnaires can be used to overcome the lack of time and resources of health professionals dealing with these patients (53).

In conclusion, the diversity of study designs (level of evidence) does not appear to affect the results of studies. Construction of a standard questionnaire and its use in studies with a high scientific level of evidence would help make the differences found in the HRQoL become an important element in planning treatment for patients with oral cancer. 
Table 2. Summary of main findings/conclusions from studies, according to study design and level of evidence.

Randomized clinical trial, with level of evidence 1++ (54).

-Changes in the amplitude of the shoulder at six weeks and at six months are associated with changes in the HRQoL

Randomized clinical trial, with level of evidence 1+

-The patients who are trained in swallowing obtain better scores on the HRQoL questionnaire than the patients who receive no such training (55).

Controlled cohorts, with level of evidence $2+$

-The average impact on oral HRQoL (OHRQoL) is between $29 \%$ and $71 \%$ higher (worst OHRQoL) in the patients than in the general population (21).

-In terms of HRQoL, there is no consensus. Some studies report it to be worse than for the control cohort [two times as many subjects in the patient cohort affirms having problems in at least one domain (56), or the mean scores in their QOL are between 7\% and 78\% less (57)], whereas other studies find them to be similar (3,45,49,58-60).

-Patients who have not received radiotherapy have higher salivary flow rates and significant better results for physical function, dyspnea, swallowing, social eating, dry mouth and nutritional support (61).

Non-controlled cohorts, with level of evidence 3

-Better HRQoL before and six months after treatment are predicting factors of greater survival rates $(22,36,62)$.

-Patients receiving combined treatment (surgery plus radiotherapy and/or chemotherapy) have between $10 \%$ and $28 \%$ lower mean scores in HRQoL one year after treatment as opposed to patients who have only surgical treatment $(15,35,37-39,63)$, and as much as $54 \%$ less in domains such as chewing or dryness of the mouth $(36,64)$

-Compared with pre-treatment, the mean scores in HRQoL are between $8 \%$ and $31 \%$ lower after treatment $(14,15,17-20,22,65,66)$. Accordingly, at one year's time, they are $1 \%$ to $20 \%$ better $(15,17,18,46,65)$, or scores similar to those of pre-treatment are obtained $(22,42,43,45,50,67,68)$.

-Survivors present a significantly reduced overall rating of HRQoL at 1 year follow-up (69).

-Patients with larger tumours and neoplasms in the posterior part of the mouth present poorer quality of life (28).

-Hyperbaric oxygen therapy may positively influence the long-term radiotherapy sequelae (70).

-Older age, eating difficulty, speech difficulty, and depression are significant predictors of orofacial pain generated after surgical and radiation therapy (71).

-The functional results of soft palate reconstruction are superior to total anterior tongue resection (72),

Cross-sectional studies, with level of evidence 3

-Patients with a tumor over 4 centimeters in size have average scores in domains such as physical state, cognitive function, eating in public or dryness of the mouth that are $11 \%$ to $70 \%$ lower than patients with smaller tumors $(4,23,27,31)$.

-Patients treated with radiotherapy have mean HRQoL scores $8 \%$ lower than patients who do not receive radiotherapy (34). In domains such as eating or chewing the mean scores may be as much as $29 \%$ lower $(5,33,34,40)$.

-Chemotherapy, as the initial treatment, combined with radiotherapy or followed by surgery, leads to HRQoL scores similar to those obtained with other therapies (surgery followed by radiotherapy) $(73,74)$.

-There are authors who find that the type of mandibular resection does not affect HRQoL (33). Others conclude that patients with continuity resections have significantly worse values in the HRQoL domains than patients with only partial resections (75). Restoration of mandibular continuity after hemimandibulectomy leads to improved function and a superior HRQoL in appropriately selected patients (76).

-The existence of functional problems is associated with higher levels of depression $(4,77,78)$ and with impairment of postoperative HRQoL $(79,80)$.

-After treatment of oral cancer and prosthetical rehabilition, men show a significantly higher OHRQoL than women (81).

-HRQoL is similar between patients treated with selective neck dissection and patients treated with sentinel node biopsy procedure (82).

-After ablation surgeries, patients reconstructed with free flap have better speech and shoulder functions as well as better mood status than patients reconstructed with pectoralis major myocutaneous flap (83). When the reconstruction with free flap involves the commissure, HRQoL is lower than other places in the oral cavity (84). Patients who have had resections and reconstruction with free anterolateral thigh perforator flaps describe problems with chewing, taste and saliva and low scores in the domains handicap, psychological disability and social disability (85).

-Older patients (65 years or over) report better physical and emotional function than younger patients $(86,87)$.

-Prevalence of clinical anxiety and depression is within the range $22 \%-32 \%$ in the patients that underwent major surgery (88).

-Primary radiation for advanced base of tongue cancer achieves excellent functional status and HRQoL (89-91). Total glossectomy produces important problems with eating, speaking and socializing $(92,93)$.

- Local reconstructive methods are successful in the management of early oral cancers involving the tongue and floor of mouth and patients report satisfactory levels of quality of life (94).

Reviews, with level of evidence 4

-With regard to gender, there is no consensus about the existence of differences in HRQoL $(2,6)$.

-Regarding age, young patients have a poorer emotional function and a greater risk of psychological stress. Older patients have poorer scores in physical function $(2,6)$.

-Poorer HRQoL is seen with tumors located in the posterior region, larger tumors and patients who are treated with radiotherapy or cervical surgery $(2,6,47)$.

-Prospective studies are needed over longer time periods to define the duration of symptoms (95). 


\section{References}

1. Ferlay J, Shin HR, Bray F, Forman D, Mathers C, Parkin DM. Cancer Incidence, Mortality and Prevalence Worldwide in 2008. France: IARC, International Agency for Research on Cancer. 2010;127:2893-917. 2. Chandu A, Smith ACH, Rogers SN. Health-related quality of life in oral cancer: A review. J Oral Maxillofac Surgery. 2006;64:495-502.

3. Jenewein J, Zwahlen RA, Zwahlen D, Drabe N, Moergeli H, Buchi S. Quality of life and dyadic adjustment in oral cancer patients and their female partners. Eur J Cancer Care. 2008;17:127-35.

4. Hassanein K, Musgrove BT, Bradbury E. Functional status of patients with oral cancer and its relation to style of coping, social support and psychological status. Br J Oral Maxillofac Surg. 2001;39:340-5.

5. Gurney TA, Eisele DW, Orloff LA, Wang SJ. Predictors of quality of life after treatment for oral cavity and oropharyngeal carcinoma. Otolaryngol Head Neck Surg. 2008;139:262-7.

6. Torres-Carranza E, Infante-Cossio P, Hernández-Guisado JM, Hens-Aumente E, Gutiérrez-Perez JL. Assessment of quality of life in oral cancer. Med Oral Patol Oral Cir Bucal. 2008;13:735-41.

7. Wilton NK, Slim AM. Application of the principles of evidencebased medicine to patient care. South Med J. 2012;105:136-43.

8. Rogers SN, Ahad SA, Murphy AP. A structured review and theme analysis of papers published on 'quality of life' in head and neck cancer: 2000-2005. Oral Oncol 2007;43:843-68.

9. Harbour R, Miller J, for the Scottish Intercollegiate Guidelines Network Grading Review Group. A new system for grading recommendations in evidence based guidelines. BMJ. 2001;323:334-36.

10. Schulz KF, Altman DG, Moher D, for the CONSORT Group. CONSORT 2010 Statement: updated guidelines for reporting parallel group randomised trials. Ann Int Med. 2010;152:726-32.

11. Strobe Group. STROBE checklist for cohort, case-control, and cross-sectional studies (combined) 2007 [cited 2012-11-12]. Available from: http://www.strobe-statement.org/fileadmin/Strobe/uploads/checklists/STROBE_checklist_v4_combined.pdf

12. European Commission. Summary of Focus Group [cited 2012-1116]. Available from: http://ec.europa.eu/europeaid/evaluation/methodology/tools/too_fcg_en.htm.

13. Semple CJ, McGowan B. Need for appropriate written information for patients, with particular reference to head and neck cancer. $\mathrm{J}$ Clin Nurs. 2002;11:585-93.

14. Bundgaard T, Tandrup O, Elbrond O. A functional evaluation of patients treated for oral cancer. A prospective study. Int J Oral Maxillofac Surg. 1993;22:28-34.

15. Rogers SN, Lowe D, Brown JS, Vaughan ED. The University of Washington head and neck cancer measure as a predictor of outcome following primary surgery for oral cancer. Head Neck. 1999;21:394401.

16. Rogers SN, Lowe D, Fisher SE, Brown JS, Vaughan ED. Healthrelated quality of life and clinical function after primary surgery for oral cancer. Brit J Oral Maxillofac Surg. 2002;40:11-8

17. Schliephake H, Jamil MU. Prospective evaluation of quality of life after oncologic surgery for oral cancer. Int J Oral Maxillofac Surg. 2002;31:427-33.

18. Kessler PA, Bloch-Birkholz A, Leher A, Neukam FW, Wiltfang J. Evaluation of quality of life of patients with oral squamous cell carcinoma. Comparison of two treatment protocols in a prospective study. Radiother Oncol. 2004;70:275-82.

19. Biazevic MGH, Antunes JLF, Togni J, de Andrade FP, de Carvalho MB, Wunsch V. Immediate impact of primary surgery on health-related quality of life of hospitalized patients with oral and oropharyngeal cancer. J Oral Maxillofac Surg. 2008;66:1343-50.

20. Villaret AB, Cappiello J, Piazza C, Pedruzzi B, Nicolai P. Quality of life in patients treated for cancer of the oral cavity requiring reconstruction: a prospective study. Acta Otorhinolaryngol Ital. 2008;28:120-5.

21. Hassel AJ, Danner D, Freier K, Hofele C, Becker-Bikowski K, Engel M. Oral health-related quality of life and depression/anxiety in long-term recurrence-free patients after treatment for advanced oral squamous cell cancer. J CranioMaxilloFac Surg. 2012;40:99-102.
22. Tarsitano A, Pizzigallo A, Ballone E, Marchetti C. Health-related quality of life as a survival predictor for patients with oral cancer: is quality of life associated with long-term overall survival? Oral Surg Oral Med Oral Pathol Oral Radiol. 2012;114: 756-63.

23. Teichgraeber J, Bowman J, Goepfert H. New test series for the functional evaluation of oral cavity cancer. Head Neck. 1985;8:9-20. 24. Harrison LB, Zelefsky MJ, Armstrong JG, Casper E, Gaynor JJ, Sessions RB. Performance status after treatment for squamous cell cancer of the base of tongue- a comparison of primary radiation therapy versus primary surgery. Int J Radiation Oncology Biol Phys. 1994;30:953-7.

25. Moore GJ, Parsons JT, Mendenhall WM. Quality of life outcomes after primary radiotherapy for squamous cell carcinoma of the base of tongue. Int J Radiation Oncology Biol Phys. 1996;36:351-4.

26. Zelefsky MJ, Gaynor J, Kraus D, Strong EW, Shah JP, Harrison LB. Long-term subjective functional outcome of surgery plus postoperative radiotherapy for advanced stage oral cavity and oropharyngeal carcinoma. Am J Surg. 1996;171:258-61.

27. Chandu A, Sun KC, DeSilva RN, Smith AC. The assessment of quality of life in patients who have undergone surgery for oral cancer: a preliminary report. J Oral Maxillofac Surg. 2005;63:1606-12. 28. Andrade FP, Antunes JL, Durazzo MD. Evaluation of the quality of life of patients with oral cancer in Brazil. Braz Oral Res. 2006;20:290-6.

29. Carranza ET, Cossio PI, Guisado JMH, Aumente EH, Perez JLG. Assessment of quality of life in oral cancer. Med Oral Patol Oral Cir Bucal. 2008;13:735-41.

30. Maciejewski O, Smeets R, Gerhards F, Kolk A, Kloss F, Stein $\mathrm{JM}$, et al. Gender specific quality of life in patients with oral squamous cell carcinomas. Head Face Med. 2010;6:21.

31. Dwivedi RC, Chisholm EJ, Khan AS, Harris NJ, Bhide SA, St Rose S, et al. An exploratory study of the influence of clinico-demographic variables on swallowing and swallowing-related quality of life in a cohort of oral and oropharyngeal cancer patients treated with primary surgery. Eur Arch Otorhinolaryngol. 2012;269:1233-9.

32. de Graeff A, de Leeuw JRJ, Ros WJG, Hordijk GJ, Blijham GH, Winnubst JAM. A prospective study on quality of life of patients with cancer of the oral cavity or oropharynx treated with surgery with or without radiotherapy. Oral Oncol. 1999;35:27-32.

33. Van Cann EM, Dom M, Koole R, Merkx MAW, Stoelinga PJW. Health related quality of life after mandibular resection for oral and oropharyngeal squamous cell carcinoma. Oral Oncol 2005;41:687-93. 34. Smith GI, Yeo D, Clark J, Choy ET, Gao K, Oates J, et al. Measures of health-related quality of life and functional status in survivors of oral cavity cancer who have had defects reconstructed with radial forearm free flaps. Br J Oral Maxillofac Surg. 2006;44:187-92.

35. Woolley E, Magennis P, Shokar P, Lowe D, Edwards D, Rogers $\mathrm{SN}$. The correlation between indices of deprivation and health-related quality of life in patients with oral and oropharyngeal squamous cell carcinoma. Brit J Oral Maxillofac Surg. 2006;44:177-86.

36. Nordgren M, Hammerlid E, Bjordal K, Ahlner-Elmqvist M, Boysen M, Jannert M. Quality of life in oral carcinoma: A 5-year prospective study. Head Neck. 2008;30:461-70.

37. Rogers SN, Scott J, Chakrabati A, Lowe D. The patients' account of outcome following primary surgery for oral and oropharyngeal cancer using a 'quality of life' questionnaire. Eur J Cancer Care. 2008; 17:182-8.

38. Infante-Cossio P, Torres-Carranza E, Cayuela A, Hens-Aumente E, Pastor-Gaitan P, Gutierrez-Perez JL. Impact of treatment on quality of life for oral and oropharyngeal carcinoma. Int J Oral Maxillofac Surg. 2009;38:1052-8.

39. Korfage A, Schoen PJ, Raghoebar GM, Bouma J, Burlage FR, Roodenburg JLN, et al. Five-year follow-up of oral functioning and quality of life in patients with oral cancer with implant-retained mandibular overdentures. Head Neck. 2011;33:831-9.

40. Bekiroglu F, Ghazali N, Laycock R, Katre C, Lowe D, Rogers $\mathrm{SN}$. Adjuvant radiotherapy and health-related quality of life of patients at intermediate risk of recurrence following primary surgery for oral squamous cell carcinoma. Oral Oncol. 2011;47:967-73. 
41. Schliephake H, Neukam FW, Schmelzeisen R, Varoga B, Schneller H. Long-term quality of life after ablative intraoral tumor surgery. Journal Craniomaxillofac Surg. 1995;23:243-9.

42. Schliephake H, Rüffert K, Schneller T. Prospective Study of the Quality of Life of Cancer Patients After Intraoral Tumor Surgery. J Oral Maxillofac Surg. 1996;54:664-9.

43. Rogers SN, Humphris G, Lowe D, Brown JS, Vaughn ED. The impact of surgery for oral cancer on quality of life as measured by the Medical Outcomes Short Form 36. Oral Oncol. 1998;34:171-9.

44. Rogers SN, Lowe D, Brown JS, Vaughan ED. A comparison between the University of Washington Head and Neck Disease-Specific Measure and the Medical Short Form 36, EORTC QOQ-C33 and EORTC Head and Neck 35. Oral Oncol. 1998;34:361-72.

45. Herce J, Rollón A, Polo J. Calidad de vida en pacientes intervenidos de cáncer bucal con supervivencia superior a 5 a-os: comparación con los valores de referencia de la población espa-ola. Med Clin. 2007;128:692-6.

46. Lee HF, Liu HE. Prospective changes of the quality of life for patients newly diagnosed with oral cancer during the acute stage. Eur J Oncol Nurs. 2010;14:310-5.

47. Rogers SN. Quality of life perspectives in patients with oral cancer. Oral Oncol. 2010;46:445-7.

48. Rogers S. Quality of life for head and neck cancer patients - has treatment planning altered? Oral Oncol. 2009;45:435-9.

49. Zwahlen RA, Dannemann C, Graetz KW, Studer G, Zwahlen D, Moergeli $\mathrm{H}$, et al. Quality of life and psychiatric morbidity in patients successfully treated for oral cavity squamous cell cancer and their wives. J Oral Maxillofac Surg. 2008;66:1125-32.

50. Schliephake H, Neukam FW, Schmelzeisen R, Varoga B, Schneller H. Long-term quality of life after ablative intraoral tumor surgery. J Craniomaxillofac Surg. 1995;23:243-9.

51. Newell R, Ziegler L, Stafford N, Lewin RJ. The information needs of head and neck cancer patients prior to surgery. Ann R Coll Surg Eng1. 2004;86:407-10.

52. Ziegler L, Newell R, Stafford N, Lewin R. A literature review of head and neck cancer patients information needs, experiences and views regarding decision-making. Eur J Cancer Care. 2004:13:119-26.

53. Millsopp L, Frackleton S, Lowe D, Rogers SN. A feasibility study of computer assisted health-related quality of life data collection in patients with oral and oropharyngeal cancer. Int J Oral Maxillofac Surg. 2006;35:761-4.

54. Parikh S, Tedman BM, Scott B, Lowe D, Rogers SN. A double blind randomised trial of IIb or not IIb neck dissections on electromyography, clinical examination, and questionnaire-based outcomes: a feasibility study. Br J Oral Maxillofac Surg. 2012;50:394-403.

55. Zhen Y, Wang J, Tao D, Wang HJ, Chen WL. Efficacy survey of swallowing function and quality of life in response to therapeutic intervention following rehabilitation treatment in dysphagic tongue cancer patients. Eur J Oncol Nurs. 2012;16:54-8.

56. Rogers SN, Miller RD, Ali K, Minhas AB, Williams HF, Lowe D. Patients' perceived health status following primary surgery for oral and oropharyngeal cancer. Int J Oral Maxillofac Surg. 2006;35:913-9.

57. Fang FM, Tsai WL, Chien CY, Chiu HC, Wang CJ. Health-related quality of life outcome for oral cancer survivors after surgery and postoperative radiotherapy. Jpn J Clin Oncol. 2004;34:641-6.

58. Freedlander E, Espie CA, Campsie LM, Soutar DS, Robertson AG. Functional implications of major surgery for intraoral cancer. $\mathrm{Br}$ J Plast Surg. 1989;42:266-9.

59. Netscher DT, Meade RA, Goodman CM, Alford EL, Stewart MG. Quality of Life and Disease-Specific Functional Status following Microvascular Reconstruction for Advanced (T3 and T4) Oropharyngeal Cancers. Plast Reconstr Surg. 2000;105:1628-34.

60. Lopez JH, Mayordomo AR, Rosado RL, Fernandez CIS, Gallana S. Quality of Life in Long-Term Oral Cancer Survivors: A Comparison With Spanish General Population Norms. J Oral Maxillofac Surg. 2009;67:1607-14.

61. Al-Nawas B, Al-Nawas K, Kunkel M, Grötz KA. Quantifying radioxerostomia: salivary flow rate, examiner's score, and quality of life questionnaire. Strahlenther Onkol. 2006;182:336-41.

62. Oskam IM, Verdonck-de Leeuw IM, Aaronson NK, Kuik DJ, de Bree R, Doornaert P, et al. Quality of life as predictor of survival: A prospective study on patients treated with combined surgery and radiotherapy for advanced oral and oropharyngeal cancer. Radiother Oncol. 2010; 97:258-62.

63. Zuydam AC, Lowe D, Brown JS, Vaughan ED, Rogers SN. Predictors of speech and swallowing function following primary surgery for oral and oropharyngeal cancer. Clin Otolaryngol. 2005;30:428-37. 64. Rogers SN, Devine J, Lowe D, Shokar P, Brown JS, Vaughan ED. Longitudinal health-related quality of life after mandibular resection for oral cancer: A comparison between rim and segment. Head Neck. 2004;26:54-62.

65. Rogers SN, Lowe D, Fisher SE, Brown JS, Vaughan ED. Healthrelated quality of life and clinical function after primary surgery for oral cancer. Br J Oral Maxillofac Surg. 2002;40:11-8.

66. Shepherd KL, Fisher SE. Prospective evaluation of quality of life in patients with oral and oropharyngeal cancer: from diagnosis to three months post-treatment. Oral Oncol. 2004;40:751-7.

67. Borggreven PA, Aaronson NK, Verdonck-de Leeuw IM, Muller MJ, Heiligers M, de Bree R, et al. Quality of life after surgical treatment for oral and oropharyngeal cancer: A prospective longitudinal assessment of patients reconstructed by a microvascular flap. Oral Oncol. 2007;43:1034-42.

68. Chen SC, Lai YH, Liao CT, Lin CC, Chang JT. Changes of symptoms and depression in oral cavity cancer patients receiving bradiation therapy. Oral Oncol. 2010;46:509-13.

69. Biazevic MGH, Antunes JLF, Togni J, Andrade FP, Carvalho MB, Wünsch-Filho V. Survival and quality of life of patients with oral and oropharyngeal cancer at 1-year follow-up of tumor resection. J Appl Oral Sci. 2010;18:279-84.

70. Gerlach NL, Barkhuysen R, Kaanders JH, Janssens GO, Sterk W, Merkx MA. The effect of hyperbaric oxygen therapy on quality of life in oral and oropharyngeal cancer patients treated with radiotherapy. Int J Oral Maxillofac Surg. 2008;37:255-9.

71. Chen SC, Liao CT, Chang JT. Orofacial pain and predictors in oral squamous cell carcinoma patients receiving treatment. Oral Oncol. 2011;47:131-5.

72. Brown JS, Rogers SN, Lowe D. A comparison of tongue and soft palate squamous cell carcinoma treated by primary surgery in terms of survival and quality of life outcomes. Int J Oral Maxillofac Surg. 2006;35:208-14.

73. Klug C, Neuburg J, Glaser C, Schwarz B, Kermer C, Millesi W. Quality of life 2-10 years after combined treatment for advanced oral and oropharyngeal cancer. Int J Oral Maxillofac Surg. 2002;31:664-9.

74. Mowry SE, Lotempio MM, Blackwell KE, Wang MB. Quality of life in advanced oropharyngeal carcinoma after chemoradiation versus surgery and radiation. Laryngoscope. 2006;116:1589-93.

75. Becker ST, Menzebach M, Küchler T, Hertrampf K, Wenz HJ, Wiltfang J. Quality of life in oral cancer patients-Effects of mandible resection and socio-cultural aspects. J CranioMaxilloFac Surg. 2012;40:24-7.

76. Wilson KM, Rizk NM, Armstrong SL, Gluckman JL. Effects of hemimandibulectomy on quality of life. Laryngoscope. 1998;108:1574-7.

77. Morton RP, Davies AD, Baker J, Baker GA, Stell PM. Quality of life in treated head and neck cancer patients: a preliminary report. Clin Otolaryngol Allied Sci. 1984;9:181-5.

78. Airoldi M, Garzaro M, Raimondo L, Pecorari G, Giordano $\mathrm{C}$, Varetto A, et al. Funcional and psychological evaluation after flap reconstruction plus radiotherapy in oral cancer. Head Neck. 2011;33:458-68.

79. Gellrich NC, Schimming R, Schramm A, Schmalohr D, Bremerich A, Kugler J. Pain, function, and psychologic outcome before, during, and after intraoral tumor resection. J Oral Maxillofac Surg. 2002;60:772-7.

80. Handschel J, Naujoks C, Kübler NR, Krüskemper G. Fear of 
recurrence significantly influences quality of life in oral cancer patients. Oral Oncol. 2012;48:1276-80.

81. Linsen S, Schmidt-Beer U, Fimmers R, Gruner M, Koeck B. Craniomandibular Pain, Bite Force, and Oral Health-Related Quality of Life in Patients with Jaw Resection. J Pain Symptom Manage. 2009;37:94-106.

82. Schiefke F, Akdemir M, Weber A, Akdemir D, Singer S, Frerich B. Function, postoperative morbidity, and quality of life after cervical sentinel node biopsy and after selective neck dissection. Head Neck. 2009;31:503-12.

83. Hsing CY, Wong YK, Wang CP, Wang CC, Jiang RS, Chen FJ, et al. Comparison between free flap and pectoralis major pedicled flap for reconstruction in oral cavity cancer patients - A quality of life analysis. Oral Oncol. 2011;47:522-7.

84. Chang KP, Lai CS, Hsieh TY, Wu YC, Chang CH. Two-year quality of life after free flap reconstruction in tumor-site discrepancy among Taiwanese with moderately advanced oral squamous cell carcinoma. World J Surg Oncol. 2012;10:145.

85. Li W, Yang Y, Xu Z, Liu F, Cheng Y, Xu L, et al. Assessment of quality of life of patients with oral cavity cancer who have had defects reconstructed with free anterolateral thigh perforator flaps. Br J Oral Maxillofac Surg. 2012; http://dx.doi.org/10.1016/j. bjoms.2012.09.005.

86. Laraway DC, Lakshmiah R, Lowe D, Roe B, Rogers SN. Quality of life in older people with oral cancer. Br J Oral Maxillofac Surg. 2012;50:715-20.

87. Herce-López J, Rollón-Mayordomo R, Lozano-Rosado P, InfanteCossio P, Salazar-Fernández CI. Assessment of quality of life of oral cancer survivors compared with Spanish population norms Int J Oral Maxillofac Surg. 2012; http://dx.doi.org/10.1016/j.ijom.2012.11.014.

88. Epie CA, Freedlander E, Campsie LM, Soutar DS, Robertson AG. Psychological distress at follow-up after major surgery for intraoral cancer. J Psychosom Res. 1989;33:441-8.

89. Harrison LB, Zelefsky MJ, Sessions RB, Fass DE, Armstrong JG, Pfister DG, et al. Base-of-tongue cancer treated with external beam irradiation plus brachytherapy: oncologic and functional outcome. Radiology. 1992;184:267-70.

90. Harrison LB, Zelefsky MJ, Pfister DG, Casper E, Raben A, Kraus $\mathrm{DH}$, et al. Detailed quality of life assessment in patients treated with primary radiotherapy for squamous cell cancer of the base of the tongue. Head Neck. 1997; 19: 169-75. PMID: 9142514

91. Robertson MT, Gleich LL, Barrett WL, Gluckman JL. Base-oftongue cancer: survival, function, and quality of life after externalbeam irradiation and brachytherapy. Laryngoscope. 2001; 111: $1362-5$.

92. Ruhl CM, Gleich LL, Gluckman JL. Survival, function, and quality of life after total glossectomy. Laryngoscope. 1997; 107: 1316-21.

93. Kazi R, Prasad V, Venkitaraman R, Nutting CM, Clarke P, RhysEvans P, et al. Questionnaire analysis of swallowing-related outcomes following glossectomy. ORL J Otorhinolaryngol Relat Spec. 2008;70:151-5.

94. Boyapati RP, Shah KC, Flood V, Stassen LF. Quality of life outcome measures using UW-QOL questionnaire v4 in early oral cancer/squamous cell cancer resections of the tongue and floor of mouth with reconstruction solely using local methods. Br J Oral Maxillofac Surg. 2012. [Epub ahead of print]http://dx.doi.org/10.1016/j. bjoms.2012.09.013.

95. Talmi YP. Quality of life issues in cancer of the oral cavity. J Laryngol Otol. 2002;116:785-90.

\section{Acknowledgements}

This study was financed by Programa de Formación del Profesorado Universitario del Ministerio de Educación, Cultura y Deporte and Research Group CTS-503 (Dental Public Health, University of Granada). 